\title{
Capsule Commentary on Duru et al., Adherence to Metformin, Statins, and ACE/ARBs Within the Diabetes Health Plan (DHP)
}

\author{
R. Brett McQueen, PhD
}

PhRMA Foundation Post Doctoral Fellow in Health Outcomes, Center for Pharmaceutical Outcomes Research (CePOR), Skaggs School of Pharmacy and Pharmaceutical Sciences, University of Colorado Anschutz Medical Campus, Aurora, CO, USA.

J Gen Intern Med 30(11): 1697

DOI: $10.1007 / \mathrm{s} 11606-015-3296-4$

(c) Society of General Internal Medicine 2015

$\mathrm{T}$ he employer-level "intent-to-treat" cohort study by Duru et al. evaluated the impact of an employer-initiated disease management program, the Diabetes Health Plan (DHP), on adherence to diabetes-related medications. ${ }^{1}$ Using a quasiexperimental design, the investigators estimated employerlevel adherence post-initiation of DHP for three medications covered by the DHP (metformin, statins, ACE/ARBs) and two medications not covered by the DHP (thyroxine, montelukast). The DHP provided enrolled participants discounted copayments for medications and provider visits, and access to online or telephone wellness coaching. There was a modest improvement in adherence to the three DHPcovered medications after 1 year.

While these results contribute to the existing literature on the inverse relationship between medication copayments and adherence, ${ }^{2-4}$ future research should test whether the modest improvement in adherence translates to clinical and economic benefits. Previous studies have suggested that lower out-ofpocket medication expenditures are associated with improved adherence, but not necessarily enough to reduce overall medical spending for patients and payers. ${ }^{3,5}$ Future studies on the DHP may include, as the investigators note, return-oninvestment (ROI) analyses focusing on outcomes such as changes in rates of hospitalization, emergency department visits, absenteeism, and short-term disability.

However, a truly comprehensive assessment of a benefit design package such as the DHP would include not only the employer perspective, but also the patient perspective. Ultimately, a diabetes intervention such as the DHP should maximize the health of a population by slowing disease progression, increasing survival and quality of life, and reducing costs to the employer and health plan. Outcomes such as clinical markers of benefit (HbAlc, blood pressure, LDL cholesterol, etc.), patient preferences, survival, and patientreported satisfaction-paired with employer-level outcomes -would form a complete picture of the tradeoffs associated with investing in the DHP.

For employers and health plans, this study provides evidence of a benefit design plan that can improve adherence for employees with diabetes. To determine whether the DHP is truly a scalable and affordable health plan for employers and health plans to purchase, it will be necessary to make the connection between adherence and outcomes that are relevant to decision-makers and patients.

Conflict of Interest: The author has no conflicts with this article.

Corresponding Author: R. Brett McQueen, PhD; PhRMA Foundation Post Doctoral Fellow in Health Outcomes, Center for Pharmaceutical Outcomes Research (CePOR), Skaggs School of Pharmacy and Pharmaceutical Sciences, University of Colorado Anschutz Medical Campus, Aurora, CO 80045, USA (e-mail: robert.mcqueen@ucdenver.edu).

\section{REFERENCES}

1. Duru OK, Turk N, Ettner S, Neugebauer R, Moin T, Li J, Kimbro L, Chan C, Luchs RH, Keckhafer A, Kirvan A, Mangione CM. Adherence to Metformin, Statins, and ACE/ARBs Within the Diabetes Health Plan (DHP). J Gen Intern Med. (Article SPI \#3284)

2. Clark B, et al. Evaluation of increased adherence and cost savings of an employer value-based benefits program targeting generic antihyperlipidemic and antidiabetic medications. J Manag Care Pharm. 2014;20(2):141-150.

3. Mann BS, et al. Association between drug insurance cost sharing strategies and outcomes in patients with chronic diseases: a systematic review. PLoS One. 2014;9(3):e89168.

4. Nair KV, et al. Prescription copay reduction program for diabetic employees: impact on medication compliance and healthcare costs and utilization. Am Health Drug Benefits. 2009;2(1):14-24.

5. Lee $\mathbf{J L}$, et al. Value-based insurance design: quality improvement but no cost savings. Health Aff (Millwood). 2013;32(7):1251-1257. 